\title{
Dexlansoprazole exposure and collagenous colitis: A case series
}

\author{
John L Daggett Jr' ${ }^{1 *}$ and Gilbert M Wilcox ${ }^{2 * *}$ \\ ${ }^{1}$ Mayo Regional Hospital, Dover-Foxcroft, ME 04426, USA \\ ${ }^{2}$ Portland Gastroenterology Center, Portland, ME, USA \\ \#Authors contributed equally
}

\begin{abstract}
Microscopic colitis, comprised of collagenous colitis and lymphocytic colitis, based on histopathologic findings, is a complex condition typically affecting elderly patients and rooted in genetic, environmental, and chemical exposures including pharmaceutical compounds. This report describes 4 patients who developed symptomatic and histopathologic collagenous colitis after exposure to dexlansoprazole. No prior association between the development of microscopic colitis and exposure to this proton pump inhibitor has been described. Clinical details and outcomes are documented, and the possible association discussed. The observations are relevant to ongoing use of this medication in clinical practice.
\end{abstract}

\section{Introduction}

Collagenous and lymphocytic colitis are chronic inflammatory diseases of the colon first described in 1976-1980 and characterized by watery diarrhea with normal appearing mucosa on endoscopic examination [1-4]. Mucosal biopsy required for diagnosis reveals a chronic inflammatory process with lymphocytic infiltration, subepithelial collagen deposition, or both. The two pathologic processes are often called microscopic colitis (MC). As described in early reports, the disease can occur as a primary event of variable severity, but it can also be associated with certain drug exposures, especially proton pump inhibitors (PPIs) such as lansoprazole [5-9]. There are no reported cases of collagenous colitis attributed to dexlansoprazole, a more recently introduced PPI. This report describes a case series of patients with collagenous colitis associated with exposure to dexlansoprazole.

\section{Cases}

Case 1 -- A 48-year-old woman presented with watery diarrhea. She had been on chronic omeprazole therapy for gastroesophageal reflux disease (GERD), but had recently experienced worsening of her GERD and omeprazole was replaced with dexlansoprazole. She then developed diarrhea and was evaluated after 3 months of exposure to the dexlansoprazole. Stool testing for infectious etiologies (c. difficile toxin, ova and parasites, giardia antigen) was unremarkable. Colonoscopy revealed a grossly normal appearing colonic mucosa, and biopsies revealed changes consistent with collagenous colitis. The patient discontinued dexlansoprazole therapy and had prompt resolution of her diarrhea. Symptoms have not recurred over the following three years.

Case 2 -- A 67-year-old woman with a history of GERD treated with oral calcium carbonate developed progressive watery diarrhea. Stool testing for infection was unremarkable. She underwent colonoscopy revealing a normal appearing colon, and biopsies revealed lymphocytic colitis. She was treated with bismuth subsalicylate for 2 weeks with resolution of diarrhea. She remained asymptomatic with normal stools until three years later when she developed recurrent diarrhea two weeks after starting dexlansoprazole for persistent GERD. Testing for infectious etiologies was negative. Five weeks after initial exposure and three weeks after stopping the dexlansoprazole she underwent repeat colonoscopy which revealed hyper vascular colonic mucosa. Biopsies showed collagenous colitis. After discontinuing the dexlansoprazole she re-initiated bismuth subsalicylate with only modest improvement, eventually requiring therapy with budesonide. She ultimately required a three-month taper of budesonide. Over the next six years she has not had recurrence of diarrhea.

Case 3 -- An 85-year-old man with a history of chronic GERD treated with omeprazole developed C. difficile diarrhea after treatment with clindamycin. This was treated with oral metronidazole with resolution. Four years later he developed a second episode of C. difficile diarrhea. Colonoscopy confirmed acute colitis and he was treated with intravenous metronidazole and oral vancomycin with improvement in his symptoms. After completing the therapy for C. difficile he was asymptomatic. Two months later the patient started dexlansoprazole for worsening of GERD and within one month he developed diarrhea. Stool testing for infection was unremarkable. He continued to have mild diarrhea prompting repeat colonoscopy showing normal mucosa, but biopsy revealed collagenous colitis with neutrophilic and lymphocytic infiltration. Dexlansoprazole was discontinued and he was started on bismuth subsalicylate with improvement in his symptoms. He was then treated with budesonide which required tapering over months and stools returned to near normal. Follow-up colon biopsy 14 months later continued to show collagenous colitis with decreased lymphocytosis. Patient has had no persistent recurrence of diarrhea over five years of follow up.

${ }^{\star}$ Correspondence to: Gilbert M Wilcox, Portland Gastroenterology Center 161 Marginal Way Portland, ME 04101, USA, E-mail: gwilcox1@maine.rr.com

Received: August 15, 2018; Accepted: September 05, 2018; Published: September 10, 2018 
Case 4 -- A 69-year-old male presented with acute diarrhea. The patient had a history of ulcerative colitis in remission for six years off treatment. A surveillance colonoscopy performed one-month prior showed normal mucosa and biopsies were negative for inflammation, dysplasia, or colitis. Two weeks prior to presentation, the patient had been switched from omeprazole to dexlansoprazole and after four days of therapy developed diarrhea. Stool testing for infection was unremarkable. Colonoscopy performed three weeks later revealed numerous regions of patchy erythema and loss of vascular pattern throughout the colon, but no areas of friability or acute colitis. Biopsies revealed collagenous colitis. Dexlansoprazole therapy was discontinued and within one week he was asymptomatic. Repeat colonoscopy five weeks after prior exam was unremarkable and mucosal biopsy was normal. Symptomatic remission has continued for 2.5 years.

\section{Discussion}

In this report we describe a series of patients who developed symptomatic collagenous colitis after exposure to dexlansoprazole suggesting an association with exposure to this PPI. Previous studies have shown that microscopic colitis is associated with multiple other drug exposures. This case series extends these observations and suggests dexlansoprazole can be the cause of some cases of collagenous colitis. An association is supported by the similarity of clinical events among the four cases. Symptoms began soon after exposure (2-12 weeks). All patients improved after drug withdrawal. No specific treatment was required in two of the cases. Finally, mucosal biopsies were similar in all cases, showing collagenous colitis and resolution or improvement was seen in the two patients who had follow-up biopsies.

There are some limitations to accepting causation as implied with our case series. First, three of our four patients had been chronically exposed to omeprazole, a potential cause of microscopic colitis [11]. The omeprazole had been well tolerated in all of these patients and had not resulted in diarrhea during therapy. While it is possible these patients may have had asymptomatic collagenous colitis from the prior PPI, the sudden onset of diarrhea associated with dexlansoprazole exposure suggests symptomatic colitis secondary to dexlansoprazole.

Next, the patient with ulcerative colitis in remission developed diarrhea following the initiation of dexlansoprazole. Inflammatory bowel disease has been possibly associated with the development of microscopic colitis and one may speculate that the dexlansoprazole therapy was only coincidental with the patient developing collagenous colitis $[12,13]$. However, the normal colon biopsies just before onset of symptoms and prompt histologic normalization after drug withdrawal argue against a relation to IBD.

Finally, one patient had a prior diagnosis of lymphocytic colitis, with interval resolution of symptoms before the development of dexlansoprazole-induced collagenous colitis. It may be argued that this patient had asymptomatic microscopic colitis prior to dexlansoprazole exposure.

In conclusion, we present a case series of four patients who developed diarrhea and histopathological changes of collagenous colitis when exposed to dexlansoprazole. Following discontinuation of dexlansoprazole all patients had improvement in their clinical symptoms and those later tested by biopsy demonstrated histopathologic improvement or resolution. Awareness of this association will be useful in the clinical use of proton pump inhibitors.

\section{Financial support}

None.

\section{Acknowledgements}

The authors would like to thank Wendy Craig of the Center for Research Outcomes for her input and feedback regarding this case series.

\section{Patient informed consent}

Clinical details retrieved from data base on microscopic colitis approved by Institutional Review Board, Maine Medical Center, Portland, ME. In preparation of this manuscript, each patient was contacted about information in the existing medical record and involved in an informed consent process. This was conducted over the telephone by Dr. Wilcox and witnessed by an unbiased third party. All patients agreed to volunteer their medical information to be documented in the below format for intent of educational and scholarly purposes. There questions were answered, and follow-up information provided should they have additional questions for the authors in the future. Additional documentation available upon request.

\section{Competing interests}

None.

\section{References}

1. Lindström CG (1976) 'Collagenous colitis' with watery diarrhoea--a new entity? Pathol Eur 11: 87-89. [Crossref]

2. Freeman H, Weinstein WST (1976) Watery diarrhea syndrome associated with a lesion of the colonic basement membrane (BM) - lamina propria (LP) interface. Ann R Coll Physician Surg Can 9: 45.

3. Nielsen VT, Vetner M, Harsløf E (1980) Collagenous colitis. Histopathology 4: 83-86 [Crossref]

4. Bogomoletz WV, Adnet JJ, Birembaut P, Feydy P, Dupont P (1980) Collagenous colitis: an unrecognised entity. Gut 21: 164-168. [Crossref]

5. Kingham JG, Levison DA, Ball JA, Dawson AM (1982) Microscopic colitis-a cause of chronic watery diarrhoea. Br Med J (Clin Res Ed) 285: 1601-1604. [Crossref]

6. Jessurun J, Giardiello FM, Hamilton SR, Bayless TM, Yardley JH (1986) Collagenous colitis: A clinicopathologic study of 15 cases. Lab Invest 54: 28A

7. Palmer KR, Berry H, Wheeler PJ, Williams CB, Fairclough P, et al. (1986) Collagenous colitis--a relapsing and remitting disease. Gut 27: 578-580. [Crossref]

8. Thomson RD, Lestina LS, Bensen SP, Toor A, Maheshwari Y, et al. (2002) Lansoprazole-associated microscopic colitis: a case series. Am J Gastroenterol 97: 2908-2913. [Crossref]

9. Wilcox GM, Mattia A (2002) Collagenous colitis associated with lansoprazole. J Clin Gastroenterol 34: 164-166. [Crossref]

10. Park T, Cave D, Marshall C (2015) Microscopic colitis: A review of etiology, treatment and refractory disease. World J Gastroenterol 21: 8804-8810. [Crossref]

11. Wilcox GM, Mattia AR (2009) Microscopic colitis associated with omeprazole and esomeprazole exposure. J Clin Gastroenterol 43: 551-553. [Crossref]

12. Ronnblom A, Holmstrom T, Tanghoi H, Wanders A, Sjöberg D (2015) Celiac disease, collagenous sprue and microscopic colitis in IBD. Observations from a populationbased cohort of IBD (ICURE). Scan J Gastroenterol 50: 1234-1240. [Crossref]

13. Jegadeesan R, Liu X, Pagadala MR, Gutierrez N, Butt M, et al. (2013) Microscopic colitis: is it a spectrum of inflammatory bowel disease? World J Gastroenterol 19: 4252-4256. [Crossref]

Copyright: C2018 Daggett JL. This is an open-access article distributed under the terms of the Creative Commons Attribution License, which permits unrestricted use, distribution, and reproduction in any medium, provided the original author and source are credited. 